\title{
Efficacy of Atropine in Treatment/Decreasing Progress of Myopia
}

\author{
Shilpa Singh ${ }^{1}$, Rajiv Kumar ${ }^{2}$ and Anurag Narula ${ }^{2 *}$ \\ ${ }^{1}$ Visitech Eye Centre, Jasola, India \\ ${ }^{2}$ VMMC and Safdarjung Hospital, India
}

Submission: July 12, 2018; Published: September 21, 2018

*Corresponding author: Anurag Narula, VMMC and Safdarjung Hospital, D-II/368 Pandara Road New Delhi-110003, India, Tel: 9990770479; Email: ananuragnarula@rediffmail.com

Abstract

Aim: To study the effectiveness of atropine in retarding progressive axial myopia in the age group 5 to 15 .

Materials and Methods: This prospective interventional cohort study included children aged 5-15 years. Both the eyes of myopic children with progressive increase of $\geq-0.5 \mathrm{D}$ sphere/year with the best-corrected vision of $\geq 6 / 6$ were treated with once a day application of $0.01 \%$ atropine eye drops. The progression of myopia after 1-year follow-up was analyzed.

Outcome measures: Outcome was measured by the visual acuity using snellens chart every month till 12 months.

Results: 50 eyes of 25 myopes were included in the study. The mean age was 10 years. The mean baseline sphere was $-5.0 \mathrm{D}$. Duration of follow-up was 12 months. The baseline rate of progression was reduced from $-0.8 \mathrm{D} /$ year (range $-0.5 \mathrm{D} / \mathrm{year}$ to $-3 \mathrm{D} / \mathrm{year}$ ) to $-0.1 \mathrm{D} / \mathrm{year}$ (range $0 \mathrm{D} /$ year to $-1.0 \mathrm{D} / \mathrm{year}$ ) after atropine therapy.

Conclusion: Atropine eye drops was well tolerated and efficacious for the retardation of progressive myopia.

\section{Introduction}

Atropine eye drops are used to retard the progression of myopia since 1960. We started using 1\% atropine eye drops for progressive simple axial myopic children aged 6-12 years following the publication of ATOM 1 study in 2006 [1]. However, that practice never became popular among the fellow ophthalmologists in India. Since the publication of the ATOM 2 study [2], we are noticing more ophthalmologists resorting to atropine eye drops to reduce the progression of myopia in children because the low-dose atropine $(0.01 \%)$ is practically free from the important side effects of blurring and photophobia. Moreover, $0.01 \%$ atropine drop does not lead to a rebound increase after a sudden cessation of treatment [3-5].

In the coming years, it is expected that a routine use of topical atropine may become an important preferred practice pattern, not only in slowing the myopic shift in the school-going children but also in the prevention of the onset of myopia in high-risk children [6,7].

$1 \%$ concentration of atropine may still be indicated for the myopes with rapid progression, higher myopia at baseline, during the years of active growth, and among the "poor" responders of lower concentrations of atropine. In ATOM 2 study, 1\% atropine drop was found to have a higher efficacy (78\%) in comparison to $0.01 \%$ (50\% efficacy) and $20 \%$ myopes were diagnosed as "poor" responders to lower concentrations of atropine (i.e., $0.01 \%, 0.1 \%$, and $0.5 \%$ ).

\section{Materials and Methods}

In this prospective interventional cohort study, we included children aged 5-15 years with the best-corrected vision $\geq 6 / 6$ and a documented myopic progression of $\geq-0.5 \mathrm{D} /$ year (calculated from sequential cycloplegic refractions of immediate past 1 year).

Only those patients who did not miss or stop the atropine eye drops during the study period were included for the analysis. The progression of myopia after 1-year follow-up was analyzed Outcome was measured by the visual acuity using snellens chart every month till 12 months. The vision and refraction assessment was done under cycloplegia with a routine use of duochrome test. Paired t-test was used as a test of significance to compare pre- and post-treatment progression.

\section{Results}

50 eyes of 25 myopes were included in the study. The mean age was 10 years. The mean baseline sphere was $-5.0 \mathrm{D}$. Duration of follow-up was12 months. The baseline rate of progression was reduced from $-0.8 \mathrm{D} /$ year (range $-0.5 \mathrm{D} /$ year to $-3 \mathrm{D} /$ year) to $-0.1 \mathrm{D} /$ year (range $0 \mathrm{D} /$ year to $-1.0 \mathrm{D} /$ year) after atropine therapy.

\section{Discussion}

There is a clear evidence that atropine eye drops has dose- 
dependent efficacy for retarding the myopia, 1\% being most effective $(78 \%)$ followed by $0.5 \%, 0.1 \%$, and $0.01 \%(50 \%$ effective) [2], and the rebound effect on cessation is least with $0.01 \%$ followed by $0.1 \%, 0.5 \%$, and $1 \%[2,3,16]$. Sudden cessation of atropine drops during the years of increasing height can be associated with the rebound increase in myopia progression $[2,3,16]$. Nevertheless, even after the rebound progression, the absolute myopia progression after 3 years was significantly lower in the atropine group compared with placebo [16].

In establishing clinical treatment algorithms, sudden stoppage of atropine 1 year or after 2 years of treatment is never necessary, and it was possible that if atropine had been continued longer in the ATOM studies, particularly in children whose myopia increased after atropine was stopped, and then, the overall effect may have been even better [2].

In ATOM 2 study, 3\%-4\% of patients developed allergic dermatitis and conjunctivitis [2]. We excluded four patients due to atropine-related side effects. Previous studies have reported a lack of any significant side effects of atropine on the intraocular pressure and accommodative amplitude, and hence, both these parameters were not evaluated in this study $[1,2]$.

Even though there was no history of raised body temperature or facial erythema in our study, the instructions to perform punctal occlusion, keeping the lid closed for 5 min after instillation of the eye drops, and wiping the atropine solution from the facial skin if there is any overspill may be given to reduce the risk of systemic side effects.

At present, questions remain [2], which children would best benefit from treatment (e.g., in terms of age, level of myopia, rate of progression, and family risk factors), when and how atropine should be started and stopped, and for how long it should be used, whether to use $1 \%$ atropine eye drops for the rapid progressors or for those who do not respond adequately to lower concentrations of atropine. More and larger surgeries are needed,

\section{References}

1. Chua WH, Balakrishnan V, Chan YH, Tong L, Ling Y, et al. (2006) Atropine for the treatment of childhood myopia. Ophthalmology 113(12): 2285-2291.

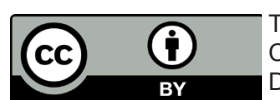

This work is licensed under Creative Commons Attribution 4.0 License DOI: 10.19080/JOJO.2018.07.555705
2. Chia A, Chua WH, Cheung YB, Wong WL, Lingham A, et al. (2012) Atropine for the treatment of childhood myopia: Safety and efficacy of $0.5 \%, 0.1 \%$, and $0.01 \%$ doses (Atropine for the treatment of myopia 2 ). Ophthalmology 119(12): 347-354.

3. Chia A, Chua WH, Wen L, Fong A, Goon YY, et al. (2014) Atropine for the treatment of childhood myopia: Changes after stopping atropine $0.01 \%, 0.1 \%$ and $0.5 \%$. Am J Ophthalmol 157(2): 451-470.

4. Tan D, Tay SA, Loh KL, Chia A (2016) Topical atropine in the control of myopia. Asia Pac J Ophthalmol (Phila) 5(6): 424-428.

5. Cooper J, Eisenberg N, Schulman E, Wang FM (2013) Maximum atropine dose without clinical signs or symptoms. Optom Vis Sci 90(12): 1467-1472.

6. Fang PC, Chung MY, Yu HJ, Wu PC (2010) Prevention of myopia onset with $0.025 \%$ atropine in premyopic children. J Ocul Pharmacol Ther 26(4): 341-345.

7. Chia A, Lu QS, Tan D (2016) Five-year clinical trial on atropine for the Treatment of myopia 2: Myopia control with atropine $0.01 \%$ eyedrops. Ophthalmology 123(2): 391-399.

8. Salazar M, Shimada K, Patil PN (1976) Iris pigmentation and atropine mydriasis. J Pharmacol Exp Ther 197(1): 79-88.

9. Lin HJ, Wan L, Tsai Y, Chen WC, Tsai SW, et al. (2009) Muscarinic acetylcholine receptor 1 gene polymorphisms associated with high myopia. Mol Vis 15: 1774-1780.

10. Anderson HA, Bertrand KC, Manny RE, Hu YS, Fern KD (2010) Comparison of two drug combinations for dilating dark irides. Optom Vis Sci 87(2): 120-124.

11. Naduvilath TJ, John RK, Dandona L (2000) Sample size for ophthalmology studies. Indian J Ophthalmol 48(3): 245-250.

12. Chia A, Chua WH, Tan D (20009) Effect of topical atropine on astigmatism. Br J Ophthalmol 93(6): 799-802.

13. Saw SM, Chua WH, Gazzard G, Koh D, Tan DT, et al. (2005) Eye growth changes in myopic children in Singapore. Br J Ophthalmol 89(11): 1489-1494.

14. McEvoy GK (2008) AHFS Drug Information. Atropine Sulfate. American Society of Health-System Pharmacists, Bethesda, MD, USA, pp. 29032904.

15. Zimmerman CF, Hogan RN, Le TD (1997) Mydriatic and cycloplegic drugs. In: Zimmerman TJ, et al. (Eds.), Textbook of Ocular Pharmacology. Lippincott-Raven, Philadelphia, USA, pp. 787-789.

16. Tong L, Huang XL, Koh AL, Zhang X, Tan DT, et al. (2009) Atropine for the treatment of childhood myopia: Effect on myopia progression after cessation of atropine. Ophthalmology 116(3): 572-579.

\section{Your next submission with Juniper Publishers will reach you the below assets}

- Quality Editorial service

- Swift Peer Review

- Reprints availability

- E-prints Service

- Manuscript Podcast for convenient understanding

- Global attainment for your research

- Manuscript accessibility in different formats

( Pdf, E-pub, Full Text, Audio)

- Unceasing customer service

Track the below URL for one-step submission https://juniperpublishers.com/online-submission.php 